
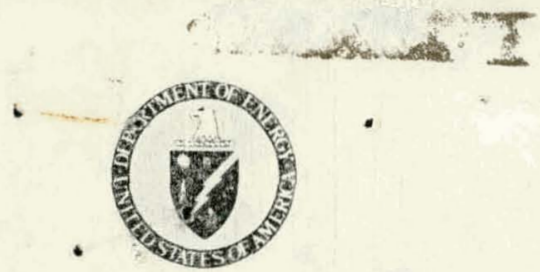

Department of Energy

Chicago Operations and Regional Office

9800 South Cass Averue

Argonne, Illinois 60439

August 21, 1980

Dr. James S. Kane, Associate Director

office of Basic Energy Sciences, HQ

Mail Station: J-309

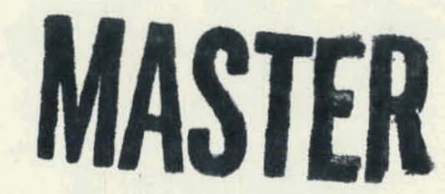

CONTRACT DE-ACO2-76ERO3158 (FORMERLY CONTRACT NO. EY-76-S-02-3158)

CORNELL UNIVERSITY

We are transmitting copies of a document submitted in accordance with our requirements under the subject contract.

AAOD: RSS

PATENT CLEARED

Rory S. Simpson, Contract Specialist BROOKHAVEN PATENT BRAMECquisition and Assistance Unit

Enclosure:

Report NO. DOE/ER/03158-91

CC: Bropkhaven Office of Patent Counsel, Brookhaven Area Office - w/encl Th chnical Information Center, Oak Ridge, TN - w/encl and 427

(THRU OFFICE OF PATENT COUNSEL - BHO)

RECEIVED

AUG $\approx 61980$

Lrive ur

PATENT COUNSEL 


\section{DISCLAIMER}

This report was prepared as an account of work sponsored by an agency of the United States Government. Neither the United States Government nor any agency Thereof, nor any of their employees, makes any warranty, express or implied, or assumes any legal liability or responsibility for the accuracy, completeness, or usefulness of any information, apparatus, product, or process disclosed, or represents that its use would not infringe privately owned rights. Reference herein to any specific commercial product, process, or service by trade name, trademark, manufacturer, or otherwise does not necessarily constitute or imply its endorsement, recommendation, or favoring by the United States Government or any agency thereof. The views and opinions of authors expressed herein do not necessarily state or reflect those of the United States Government or any agency thereof. 


\section{DISCLAIMER}

Portions of this document may be illegible in electronic image products. Images are produced from the best available original document. 


\section{$\operatorname{CONF}-800744--6$}

DIRECT OBSERVATION OF THE PRIMARY STATE OF RADIATION

DAMAGE OF ION-IRRADIATED TUNGSTEN AND PLATINUM

by

D.N. Seidman, M.I. Current, D. Pramanik and C.-Y. Wei

July 1980

Report $\# 4278$

Issued by

The Materials Science Center

Prepared for

THE U.S. DEPARTMENT OF ENERGY under Contract No. DE-A602-76ERO3158.

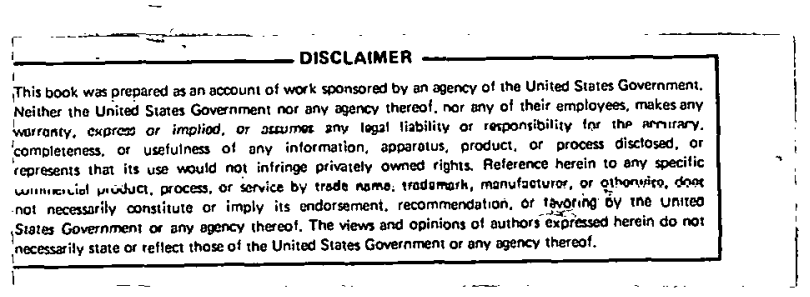

Invited paper presented at the Second International. Ion Beam Modification of Materials Conference, 1980, July 14-18, State University of New York at Albany, New York. To appear in Nur.7ea.r Tnstruments and Methode (1981). 


\title{
DIRECT OBSERVATIONS OF THE PRIMARY STATE OF RADIATION DAMAGE OF ION-IRRADIATED TUNGSTEN AND PLANTINUM ${ }^{\dagger}$
}

\author{
by \\ D.N. Seidman, M.I. Current ${ }^{*}$, D. Pramanik ${ }^{*}$ and C.-Y. Hei* \\ Cornell University, Bard Hall, Department of \\ Materials Science and Engineering and the \\ Materials Science Center \\ Ithaca, New York 14853, U.S.A.
}

\begin{abstract}
A brief summary was presented of all the Cornell work on the primary state of radiation damage in ion-irradiated tungsten and platinum. The primary research tool for all this research was the field-ion microscope (FIM); the FIM was ideally suited for this research because of its excellent atomic resolution and the ability to examine the interior of the specimens, as a result of the field-evaporation effect. This paper summarized, in outline form, the following items: (1) the principal experimental quantities determined from the analyses performed on all the individual depleted zones (DZs) observed; (2) the main experimental programs; (3) a number of the more important results and conclusions concerning the vacancy structure of DZs; and (4) the three-dimensional spatial distribution of selfinterstial atoms around $\mathrm{DZs}$ in tungsten which had been irradiated and examined in situ at $10 \mathrm{~K}$.
\end{abstract}

$+$

This research was supported by the U.S. Department of Energy under Contract No. DE-AS02-76ER03158. Additional support was received from the National Science Foundation through the use of the technical facilities of the Materials Science Center at Cornell University.

*

Now at Signetics Corporation, Sunnyvale, California 94086.

** Now at General Electric Corporate Research and Development Laboratory, Schenedtady, New York 12301. 
DIRECT OBSERVATTONS OF THE PRIMARY STATE OF RADIATION

$\therefore$ DAMAGE OF ION-IRRADIATED TUNGSTEN AND PLATINUM ${ }^{\dagger}$

\section{by}

D.N. Seidman, M.I. Current ${ }^{*}$, D. Pramanik ${ }^{*}$ and C.-Y. Wei ${ }^{* *}$

Cornell University, Bard Hall, Department of

Materials Science and Engineering and the

Materials Science Centèr

Ithaca, New York 14853, U.S.A.

The field-ion microscope (FIM) with its excellent atomic resolution and the duility to examine the interior of speclutus--as a result of tho field-evaporation effecb $[1,2]--i s$ ideally suited for the study of the properties of point defects [3-5]. As early as 1971 we : examined the point-defect structure of two depleted zones (DZs) created in tungsten, at $<15 \mathrm{~K}$, by $20 \mathrm{keV} \mathrm{W}^{+}$ions and measured the range of 25 selfinterstitial atoms (SIAs) which had been produced as a result of a series of replacement collision sequences (RCSs) [6]. This work continued with the detailed observation, in 1973, of the vacancy structure of a DZ created in tungsten at $473 \mathrm{~K}$ by a single $20 \mathrm{keV} \mathrm{W}^{+}$ion. More recently we determined the vacancy structure of a (220) platelet which had been created by a single $30 \mathrm{keV} \mathrm{W}^{+}$ion in a platinum-4 at. $\%$ gola alloy [8]. These early studies served as background experience for our more recent and rather extensive systematic studies of the primary state of damage of ion-irradiated tungsten [9-15] and platinuri [15].

$+$

This iesearth wn. oupported by the IT.S. Department of Energy under Contract No. DE-ASO2-76ER03158. Additional support was received from the National Science Foundation through the use of the technical facilities of the Materials Science Center at Cornell University.

* Now at Signeties Corporation, Sunnyvale, California 94086.

* Now at General Electric Corporate Research and Development Laboratory, Schenectady, New York 12301. 
"In general," it has been found possible to classify the vacancy portion of the primary. state of radiation damage into three morphological states: (1) depleted zones; (2) compound vacancy clusters or voids; and (3) dislocation loops. The SIAs were observed within and around isolated DZs [6,13], that had been produced in tungsten specimens maintained at $<15 \mathrm{~K}$. The values of the ion fluences employed were small enough such that each DZ was created by a single projectile ion. In the case of tungsten, the temperature of each specimen both during and after an irradiation was well below the onset of the long-range migration of SIAs [16]. Whereas, for platinum the temperature of irradiation was above the SIA long-range migration stage, that is, Stage I. All specimens were irradiated in situ under ultra-high vacuum conditions, to a dose of less than $10^{13}$ ions $\mathrm{cm}^{-2}$, and then examined in situ employing the pulse field evaporation technique [3-5].

The principal experimental quantities determined from the analyses performed on all the individual DZs observed were as follows:

(1) The direct determination of the absolute number of vacancies contained within each $\mathrm{DZ}(\nu)$ that was created by a single projectile ion of mass $\left(\mathrm{M}_{1}\right)$ and initial energy $\left(E_{1}\right)$;

(2) Visual representations of the positions of the vacancies included within every DZ--these were made employing the OR TEP program [17];

(3) The measurement of the average diameter of an individual $\mathrm{DZ}(\langle\lambda\rangle)$ and the orientation [hkl] of the DZ with respect to the ion beam and the crystal lattice;

(4) A calculation of the average vacancy concentration within each DZ ( $\left.\left\langle c_{v}\right\rangle\right)$ based on $v$ and the actual volume filled by the vacancies;

(5) A calculation of two different types of radial distribution functions $[9,1.0,1.2,1.14,15]$ for the vacancies comprising each $D Z$;

(6) The determination of the fraction of first-nearest neighbor vacancies-within each DZ--in clusters of size $n$, where $n$ ranged from one to five to approximately four hundred; 
(7) The depth (L) from the irradiated surface--measured along a direction parallel to the incident ion beam--at which the $\mathrm{DZ}$ was detected and the direction of elongation ([hkl]) of the DZ; and

(8) The measurement of the number $\left(\nu_{n s}\right)$ and concentration $\left(\left\langle c_{v}\right\rangle_{n s}\right)$ of vacancies which were created in the near-surface region ( $<5 \AA$ thick) of ion-irradiated tungsten specimens $[11,12]$.

For each experimental program listed below the physical quantities outlined in the preceeding paragraph were determined. The main experimental programs were as follows:

(1) I'he determination of the effect of $M_{7}$ on the point-def'ect structurc of $\mathrm{DZs}$, in tungstion, a.t. ronst.ant $\mathrm{E}_{1}$--the oroliectiles $\mathrm{W}^{+}, \mathrm{Mo}^{+}, \mathrm{Kr}^{+}, \mathrm{Cu}^{+}, \mathrm{Cr}^{+}$ and $\mathrm{Ar}^{+}$were employed for $\mathrm{E}_{1}=30 \mathrm{keV}$;

(2) The determination of the effect of $E_{1}$, at constant $M_{I}$, on the point-defect structure of DZs in tungsten--15, 30, 45, 60 and $\% \mathrm{KeV} \mathrm{Kr}$ ions were used as well as $20,30,45$, and $60 \mathrm{ke} \overline{\mathrm{V}} \mathrm{W}$ ions;

(3) The effect of monomer versus dimer irradiations on the point-defect structure of DZs in tungsten--the projectiles employed were $20 \mathrm{keV} \mathrm{Ag}+$ and $\mathrm{W}^{+}$, and $40 \mathrm{keV} \mathrm{Ag}{ }_{2}^{+}$ard $\mathrm{W}_{2}^{+}$ions; and

(4) In the case of tungeten the three-dimensional spatial distributions of SIAs around DZs was determined;

(5) The point-defect structure of DZs in platinum which had been irradiated with $20 \mathrm{keV} \mathrm{Kr}^{+}$ions;

(6) The sign (vacancy or SIA) and habit plane of the dislucaliun loups detected in both the Lon-irradiated platinum and tungoten specimens.

Within the context of this precis of our work it is impossible to give all the results and conclusions reached. Instead we have simply listed a number of the more important ones; the reader is referred to the refernces for further details. For the tungsten specimens the following was observed and concluded:

(1) To first order the value of $v$ was independent of $M_{1}$ and equal to approximately 172 vacancies per $\mathrm{DZ}$ for $E_{1}=30 \mathrm{keV}$;

$\uparrow$ The results that were characteristic of platinum are listed under numbers (II) and (12). 
(2) This value of $v$ was in good agreement with the Kinchin-Pease [18]

." expression as modified by Robinson and Torrens [19];

(3) The value of $\langle\lambda\rangle$ increased as $M_{1}$ was decreased at constant $\mathrm{E}_{1}(30 \mathrm{keV})$;

(4) The value of $\left\langle\mathrm{c}_{\mathrm{v}}\right\rangle$ decreased from $\approx 16$ to 2 at.\% as $M_{1}$ was decreased from $183.85 \mathrm{amu}(\mathrm{W})$ to $39.948 \mathrm{amu}(\mathrm{Ar})$ at an $\mathrm{E}_{1}$ of $30 \mathrm{keV}$;

(5) For both $K r$ and $W$ the value of $\nu$ increased linearly as $E_{1}$ was increased from 15 to $70 \mathrm{keV}$;

(6) For both $\mathrm{Kr}$ and $\mathrm{W}$ ions, with energies between 15 and $70 \mathrm{keV}$, the values of $\langle\lambda\rangle$ did not follow the trend of increasing $\langle\lambda\rangle$ predicted by the linearcascade model;

(7) The spatial arrangement of the vacancies within the DZs was a strong function of $\mathrm{M}_{1}$ at constant $\mathrm{E}_{1}(30 \mathrm{keV})--i n$ general, the number of subcascades? within each DZ increased as $M_{1}$ was decreased;

(8) The fraction of monovacancies contained within each $\mathrm{DZ}$ increased as $\mathrm{M}_{1}$ was decreased at constant $E_{1}(30 \mathrm{keV})$;

(9) The value of $\langle\nu\rangle$ per projectile ion for DZs produced by dimers was 21.5 times greater than the value of $\langle\nu\rangle$ for the DZs created by monomers--at a and constant energy per projectile ion;

(10) Statement (9) indicated the existence of strong nonlinear effects in the production of dense collision cascades;

(11) In the case of platinum, for $E_{1}=20 \mathrm{keV}$, examples of all the three morpho-logical states were found--this was not the case for tungsten irradiated with 20 and $30 \mathrm{keV}$ ions;

(12) For $E_{1}=20 \mathrm{keV}$ Krt ions, in the case of platinum, the DZs collapsed more easily to dislocation loops than in the case of tungsten--even though the average size and point-defect structure of the DZs in the two metals were similar; and

(13) The fraction of DZs that collapsed into dislocation loops in tungoten, irradiated with $W$ ions, increased as $E_{1}$ was increased from 20 to $60 \mathrm{keV}$. 
Finally, the three-dimensional spatial distribution of SIÁs around DZs, in ion-" irradiated tungsten, was determined [13]. Tungsten FIM specimens were irraciiated in situ with $30 \mathrm{keV} \mathrm{Cr}^{+}$or $18 \mathrm{keV} \mathrm{Au}^{+}$ions along the [ $\left.\overline{7} 4 \bar{I}\right]$ direction, at $10 \mathrm{~K}$, and examined at this temperature by the pulse field evaporation technique. At $10 \mathrm{~K}$ the SIAs, in tungsten, were completely immobile. The distances were measured, along the close-packed crystallographic directions--that is, the $\langle 100\rangle,\langle 110\rangle$ and $\langle 11 I\rangle-$ type direction--between each SIA and the DZs. Distance measurements were also made between each SIA and the irradiated surface of the specimen. The set of distances employed for analysis corresponded to the minimum measured distances; thus, the histograms of the distances presented represented a lower bound (denoted by $\mathrm{R}_{\min }$ ) to the actual propagation distances. For the $30 \mathrm{keV} \mathrm{Cr}^{+}$ion-irradiated specimen a total of 97 SIAs were detected and $\left\langle\mathrm{R}_{\min }>\right.$ was $175 \pm 110 \stackrel{\circ}{\mathrm{A}}$; the \pm values for $\left\langle\mathrm{R}_{\min }>\right.$ represent one standard deviation. In the case of the $18 \mathrm{keV} \mathrm{\textrm {Au } ^ { + }}$ irradiated specimen the quantity $<R_{\text {min }}>$ was $175 \pm 130 \AA$; 33 SIAs were detected. A composite distribution of $R_{\text {min }}$ values was obtained by combining our earlier measurements [6] with the present results to obtain $\left\langle\mathrm{R}_{\min }>160 \pm 120 \mathrm{~A}\right.$. We suggested that this value may have represented an overestimate of the mean range of replacement collision sequences (RCSs) in tungsten. Nevertheless, the results constituted very direct evidence for the existence of KL'Ss in tungsten. These results are consistent with our observation that the values of $<\nu>$ were in agreement with the modified Kinchin-Pease expression [18,19]. That is, the RCSs provided an et'ticlent mechanısm t'or the separation of SIAs frum lie DZs. All of the experimental results given above for DZs have been compared, in detail, with both the analytical and Monte Carlo computer simulation models of deposited energy; the reader is referred, once again, to the publications for detalis.

\section{ACKNOWLEDGEMENT}

We wish to thank Mr. Robert Whitmursh for his enthusiastic technical assistance in the experimental program. 
[1]. E:W. Müller and T.-T. Tsong, Field Ion Microscopy (American Elsevier Publishing Co., New York, 1969).

[2] E.W. Müller and T.-T. Tsong, in Progress in Surface Science, edited by S.G. Davison (Pergamon Press, New York, 1973), Vol. 4, Part 1, pp. 1-139.

[3] D.N. Seidman, J. Phys. F: Metal Phys. 3 (1973) 393.

[4] D.N. Seidman, in Radiation Damage in Metals, edited by N.L. Peterson and S.D. Harkness, (American Society for Metals, Metals Park, Ohio, 1976), pp. 28-57.

[5] D.N. Seidman, Surface Sci. 70 (1978) 532.

[6] L.A. Beavan, R.M. Scanlan and D.N. Seidman, Acta Metall. 19, (1971) 1339.

[7] K.L. Wilson and D.N. Seidman, in Defects and Defect Clusters in B.C.C. Metals and Their Alloys, edited by R.J. Arsenault (University of Marylarid, College Park, Maryland, 1973), Nuclear Metallurgy, Vol. 18, pp. 216,-239.

[8] C.-Y. Wei and D.N. Seidman, Phill. Mag. A. (1978) 257.

[9] C.-Y. Wei, Ph.D. Thesis, Comell University (1978).

[10] C.-Y. Wei and D.N. Seidman, Appl. Phys. Lett. 34, (1979) 622.

[11] M.I. Current and D.N. Seidman, Nuc. Instrum, and Methods, 170, (1980, 377.

[12] M.I. Current, C.-Y. Wei and D.N. Seidman, Cornell Materials Science Center Report No. 4193 (1980); accepted for publication in the Philosophical Magazine.

[13] C.-Y. Wei and D.N. Seidman, Cornell Materials Science Center Report No. 4088 (1980); submitted tor publication.

[14] C.-Y. Wei, M.I. Current and D.N. Seidman, Cornell Materials Science Center Report No. 4235 (1980).

[15] D. Pramanik, Ph.D. 'l'hesis, Cornell University (1.980).

[16] D.N. Seidman, K.L. W1lson and C.H. Nielsen, Phys, Rev. Lett. 35, ( J.975) 1041;

D.N. Seidman, K.L. Wilson and C.H. Nielsen, in Proc. Fundamental Aspects of Radiation Damage in Metals, edited by M.T. Robinson and F.W. Young, Jr. (National Technical Information Service, Springfield, Virginia 1975, Vol. I, pp. $373-96$. 


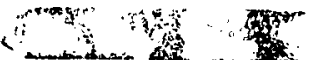

in.

:

\section{$-7-$}

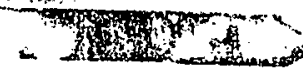

ritanten...

[17] C.K. Johnson, Oak Ridge National Laboratory Report No. 3794 plus revisions (1965) and (1970).

[18] G.H. Kinchin and R.S. Pease, Rep. Prog. Phys. 18 (1955) 1.

[19] M.T. Robinson and I.M. Torrens, Phys. Rev. B, 9 (1974) 5008. 